\title{
Dossiê Rio Doce: uma possibilidade de leitura visual em uma narrativa multimídia e multimodal
}

\author{
Rio Doce dossier: a possibility of visual reading in a \\ multimedia and multimodal narrative
}

\author{
Eliziane Cristina da Silva de Oliveira ${ }^{1}$ \\ Luana Teixeira de Souza Cruz ${ }^{2}$
}

DOI: $10.28998 / 2317-9945.2020 n 65 p 24-40$

\begin{abstract}
Resumo
Este trabalho analisa narrativas imagéticas veiculadas em ambiente digitale impresso do projeto de divulgação cientifica Minas Faz Ciência, após o rompimento da barragem de Fundão, em Mariana. O conjunto do material denominado Dossiê Rio Doce apresenta estudos desenvolvidos por cientistas de universidades e centros de pesquisa mineiros para recuperação da bacia do Rio Doce. O Dossiê, conceitualmente, é uma narrativa multimidia e multimodal que privilegion o uso de imagens e esse é o ponto principal da análise proposta: compreender a importância das imagens na construção de narrativas jornalísticas. A análise foi realizada a partir do conceito de imagem adotado por Martine Joly (2012), para quem imagem é algo que, embora nem sempre remeta ao visivel, toma alguns traços emprestados do visual e depende da produção de um sujeito que a produr ou reconhece. Estudamos o conteúdo prodųido para revista, site, Instagram e Facebook do Minas Faz Ciência, tentando compreender o "manejo" das linguagens à disposição em cada um desses suportes. Partindo dai, e considerando como particularidade do objeto analisado a necessidade de transcriação de informações científicas para um público diverso, concluímos que cada parte dessa reportagem visual - revista como carro-chefe, site como paratexto e redes sociais como elemento de ampliação e circulação - contribuiu de forma pertinente à divulgação da ciência.
\end{abstract}

Palavras-chave: Jornalismo ilustrado. Multimodalidade. Narrativa multimídia. Imagem

\begin{abstract}
This work aims to analyze the visual narratives in digital and print media of the popular science project Minas Faz Ciência. The whole of the material called Dossiê Rio Doce presents studies concerning the recovery of the Rio Doce drainage basin developed by scientists from universities and research centers of Minas Gerais. The Dossier, in conceptual terms, is a multimedia and multimodal narrative that privileges the use of images and this is the main point of the proposed analysis: to understand the importance of images in the construction of journalistic narratives. The analysis was performed based on the concept of image developed by Martine Joly (2012), who understands image as something that, although not always attached to the visible, takes some features borrowed from the visual and depends on the production of a reader that produces or recognizes. We studied the content produced for Minas Faz Ciência magazine, website, Instagram and

\footnotetext{
${ }^{1}$ Doutoranda em Estudo de Linguagens do Centro Federal de Educação Tecnológica de Minas Gerais. Professora assistente na Faculdade de Comunicação e Artes da Pontifícia Universidade Católica de Minas Gerais.

2 Doutoranda em Estudo de Linguagens do Centro Federal de Educação Tecnológica de Minas Gerais. Professora do Departamento de Comunicação do Centro Universitário Newton.
} 
Facebook, in order to understand the "manipulation" of the languages available in each of these media. Based on that, and considering the transcreation of scientific information for a diverse public as a key aspect of the object under investigation, we concluded that each part of this visual report - magazine as flagship, website as paratext and social networks as an element of expansion and circulation - bas made a relevant contribution to the dissemination of science.

Keywords: Illustrated Journalism. Multimodality. Multimedia narrative. Image

Recebido em: 08/08/2019.

Aceito em: 31/10/2019.

\section{Introdução}

Entende-se como fundamental a utilização e presença de elementos visuais nas narrativas jornalísticas. Especialmente, a importância das ilustrações, em suas diferentes formas, na compreensão das informações contidas em reportagens. A proposta deste trabalho é analisar narrativas imagéticas produzidas e veiculadas em ambiente digital (site, Instagram e Facebook) e impresso (revista trimestral) do projeto de divulgação científica Minas Faz Ciência, após o rompimento da barragem de Fundão, em Mariana. O conjunto do material, denominado Dossiê Rio Doce, apresenta estudos desenvolvidos por cientistas de universidades e centros de pesquisa mineiros para recuperação da bacia do Rio Doce. A área foi degradada pelo rompimento da Barragem de Fundão da Samarco, em 2015, que causou a morte de 18 pessoas e danos ambientais.

No caso do nosso objeto, por se tratar de divulgação científica e exigir uma aproximação maior com o público leitor, sob pena de não se permitir uma compreensão adequada do conteúdo veiculado, assumimos que imagens, embora sejam independentes da existência de texto verbal para sua compreensão, contribuem de forma decisiva na interação com as informações presentes na narrativa informativa. Em nossa análise, as imagens serão consideradas a partir da relação semântica que estabelecem com as informações textuais e audiovisuais presentes no conjunto de objetos de estudo. Essa linha de ação metodológica é respaldada pelo conceito de objeto noticioso, elaborado por Isaac Antônio Camargo (2001), que considera as relações entre os elementos que constituem as notícias veiculadas na mídia impressa, que também está presente neste trabalho (revista). Entendemos ainda que esse conceito possa ser adotado também nos demais elementos (site e Instagram) por se tratarem de plataformas com finalidades informativas (jornalísticas). Dessa forma, a configuração das notícias se dá a partir de elementos textuais e gráfico-visuais, que, no conjunto, possibilitam a produção de sentido pelos leitores. Essa escolha foi feita em função do corpus selecionado porque o conceito de objeto noticioso não se restringe à notícia, mas possibilita também o diálogo entre as notícias, as edições e até mesmo entre as publicações que compõem o corpus.

Entendemos a estrutura do objeto noticioso na mídia impressa como um discurso decorrente de relações intertextuais entre diversos elementos, ou seja, elementos da ordem do visual e do verbal. Os da ordem do visual compreendem necessariamente diversos elementos como o texto verbal, a fotografia e a organização plástica da página impressa: sua diagramação, suas cores e os tipos gráficos (família e tamanho) utilizados na construção 
de manchetes, títulos e subtítulos como também na constituição do corpo gráfico do texto. Os elementos da ordem do verbal constroem sentidos na cognição do texto impresso segundo regras e estruturas da língua, obtidos nas mesmas manchetes, legendas, bem como no discorrer do verbo impresso na constituição da notícia (CAMARGO, 2001, on-line).

Ainda que Camargo (2001) considere que nenhum dos elementos constituintes do objeto noticioso possa ser analisado isoladamente, sob pena de prejudicar a produção do sentido, nesta pesquisa nos propusemos a considerar a importância das imagens nesse conjunto, uma vez que, se o leitor-sujeito pode se apropriar primeiramente das imagens, ele pode obter informações que seriam apreendidas inicialmente no elemento textual.

É nesse contexto que se inserem as análises aqui apresentadas, partindo também do conceito adotado por Martine Joly (2012), que define imagem como "algo que, embora nem sempre remeta ao visível, toma alguns traços emprestados do visual e, de qualquer modo, depende da produção de um sujeito: imaginariamente, a imagem passa por alguém que a produz ou reconhece" (JOLY, 2012, p. 13).

\section{Dossiê Rio Doce: descrição e apresentação}

O Dossiê é um conteúdo multimídia (BARBOSA, 2013) e multimodal (RIBEIRO, 2016) desenvolvido pela equipe do projeto Minas Faz Ciência (MFC), trabalho de divulgação científica da Fundação de Amparo à Pesquisa do Estado de Minas Gerais (FAPEMIG). O conjunto contempla a apresentação de estudos desenvolvidos por cientistas de universidades e centros de pesquisa mineiros - e fomentados pela FAPEMIG - para recuperação da bacia do Rio Doce. A área foi degradada pelo rompimento da Barragem do Fundão, da Samarco, em 2015. A linha editorial do Dossiê é voltada a mostrar novas perspectivas e a esperança trazidas pela ciência à região atingida pelo maior desastre ambiental do país, até então.

O Dossiê, dotado de serialidade, é composto por três reportagens publicadas nas edições trimestrais de números 73,74 e 75 da revista MFC. O primeiro texto contempla uma visão geral de diversas pesquisas realizadas nos municípios localizados no entorno da Bacia do Rio Doce. A reportagem é o conteúdo de capa da edição, que inclusive inspirou uma arte com referência às possibilidades de recuperação da região, com o nascimento de uma pequena planta em meio ao solo devastado pela lama da barragem (ver figura 1). O segundo texto, que também tem uma chamada na capa da revista, está focado em projetos de recuperação da qualidade da água da bacia hidrográfica do Rio Doce (figura 2). E a última matéria destaca estudos sobre preservação da biodiversidade na região. Ao todo, foram 16 páginas dedicadas ao Dossiê nas três edições analisadas. 
Figura 1 - Capa da edição 73 da Revista Minas Faz Ciência.

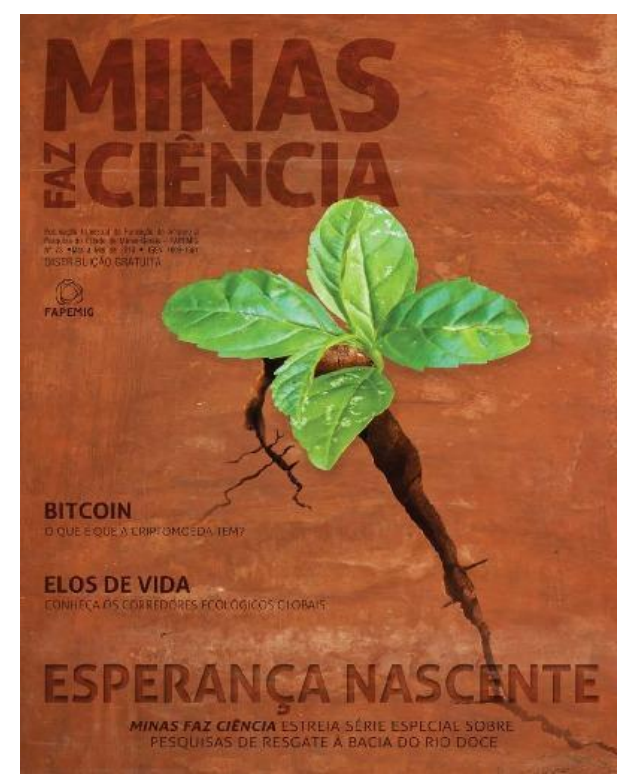

Fonte: FAPEMIG (2018). Disponível em: https://issuu.com/fapemig. Acesso em: 3 dez. 2019.

Figura 2 - Aberturas das reportagens das edições da revista impressa.

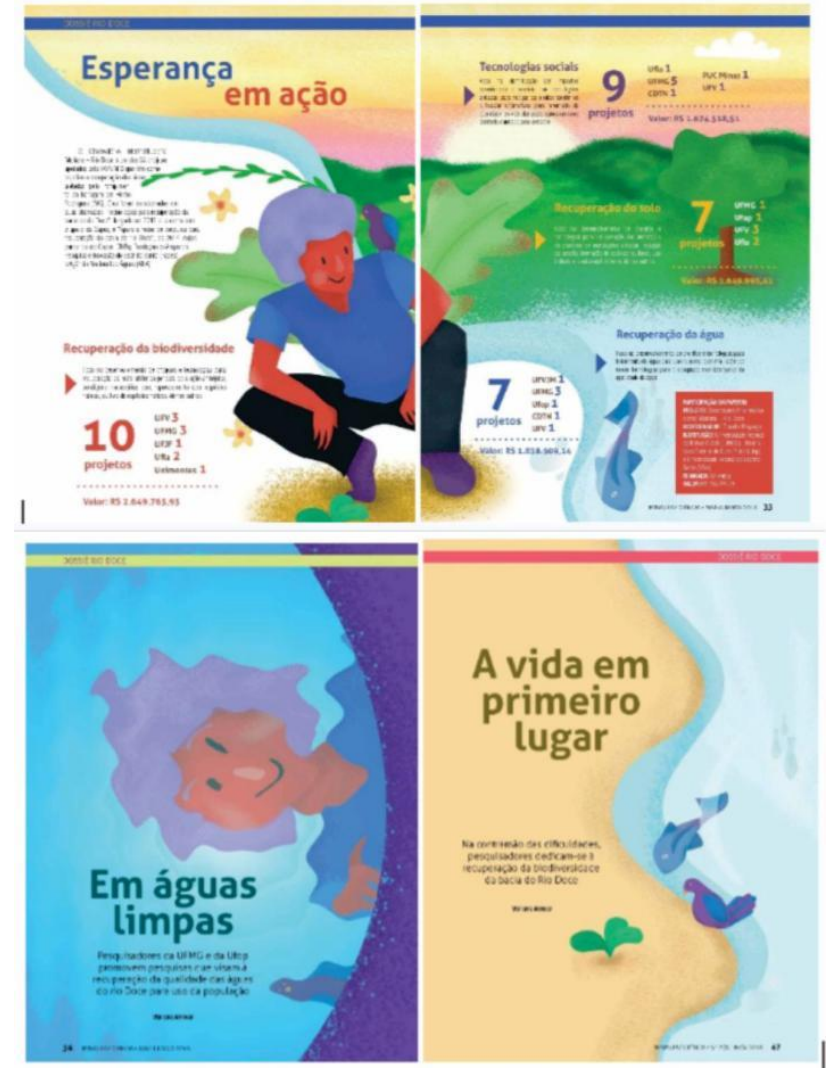

Fonte: FAPEMIG (2018). Disponível em: https://issuu.com/fapemig. Acesso em: 3 dez. 2019. 
Além do material impresso, foi elaborado o conteúdo digital que relata, de forma multimodal, os bastidores de uma das pesquisas científicas. O especial "Expedição Rio Doce" (figura 3) está publicado em local especial no site do projeto MFC e conta com material em textos, vídeos e fotos. A equipe de jornalistas viajou com pesquisadores e passou três dias registrando o trabalho de campo que tinha como objetivo coletar folhas e sementes de espécies vegetais típicas da Mata Atlântica para realizar estudo sobre a importância dos fungos na preservação ambiental.

Figura 3 - Reprodução do Especial Expedição Rio Doce, material publicado no site do programa MFC.

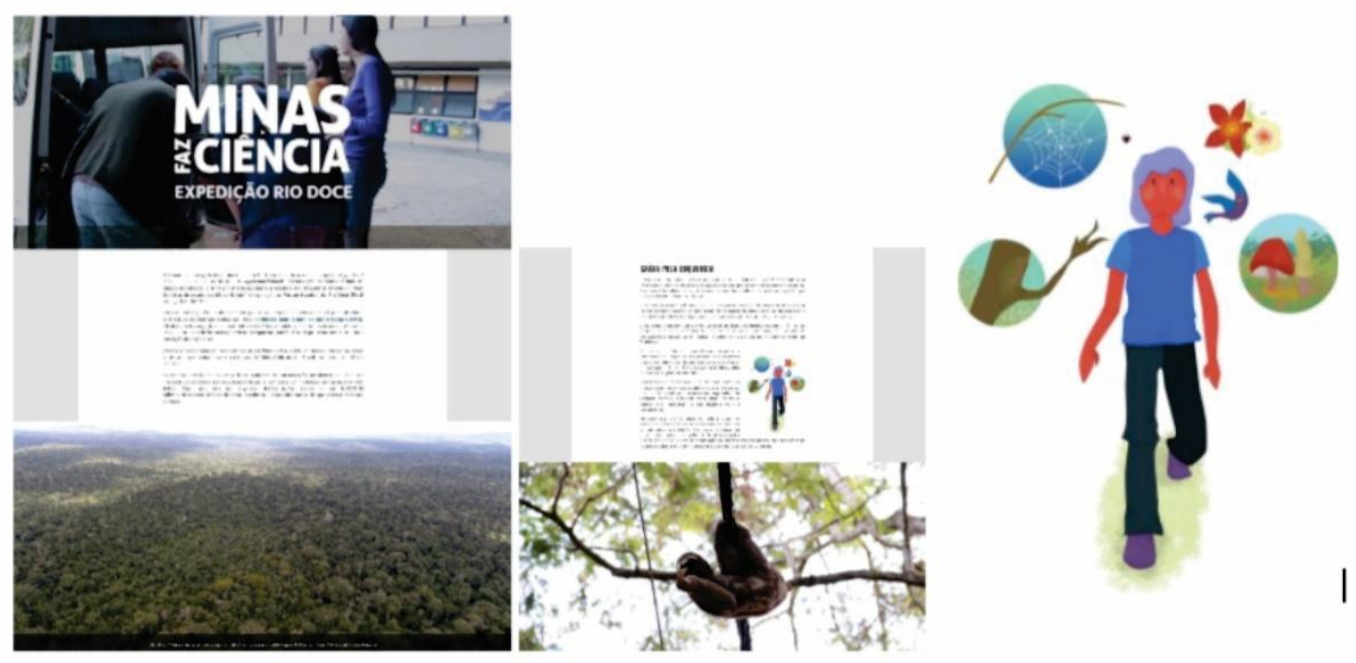

Fonte: FAPEMIG (2018). Disponível em: http://minasfazciencia.com.br/expedicao-rio-doce/. Acesso em: 3 dez. 2019.

Ademais, o conteúdo do Dossiê circulou nas mídias sociais com criações específicas para duas plataformas: Facebook e Instagram. Para a primeira, publicou-se um vídeo de animação (figura 4) lançado como capa do perfil MFC assim que a revista impressa foi distribuída aos leitores. No caso do Instagram, o formato escolhido foi de combinação de um mosaico em que cada imagem se desdobrava em um carrossel (ver figura 5).

Figura 4 - Reprodução vídeo para Facebook.

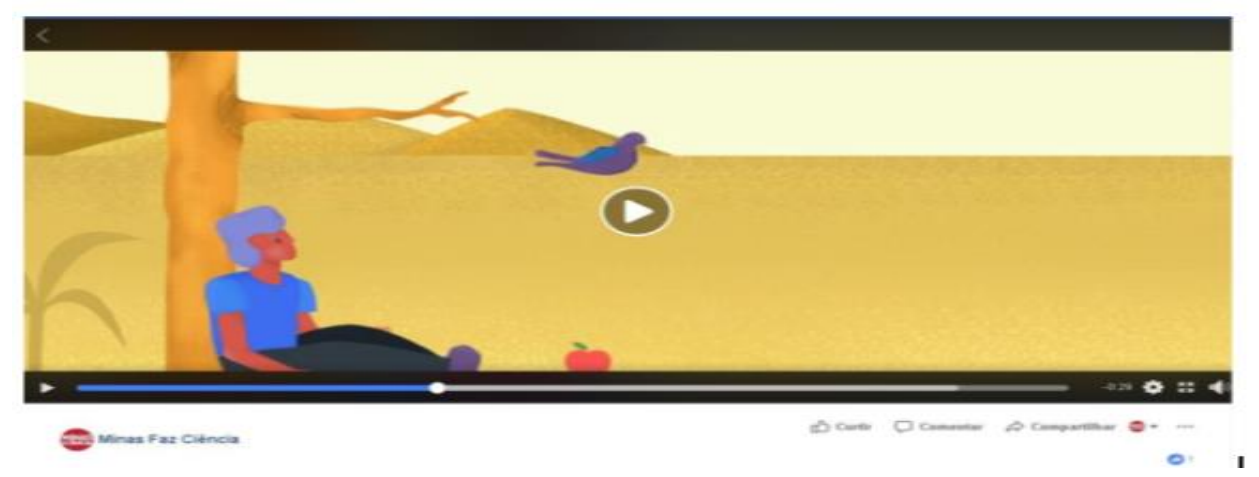

Fonte: Facebook Minas Faz Ciência (2018): Disponível em: https://goo.gl/1ucAqj. Acesso em: 3 dez. 2019. 
Figura 5 - Reprodução do mosaico perfil do Instagram.
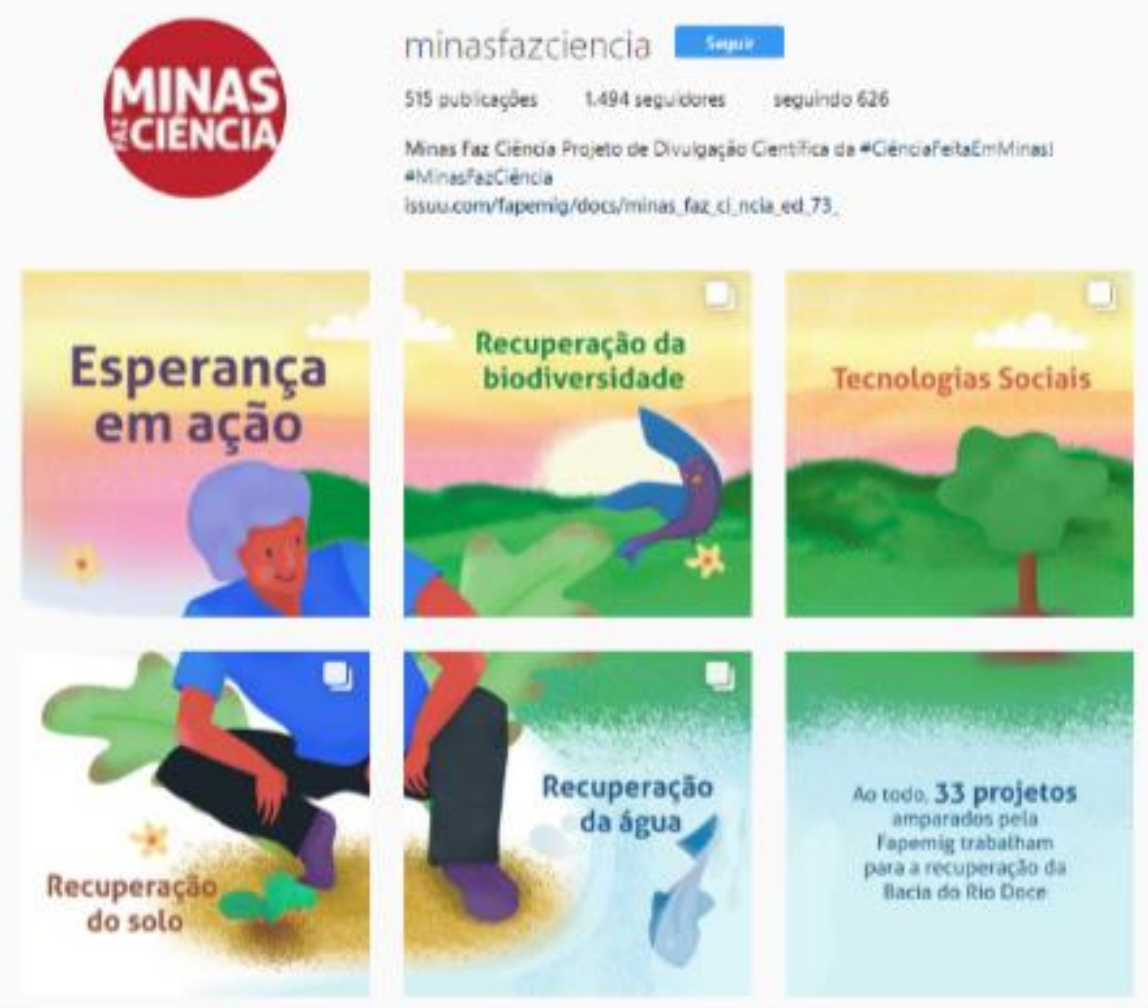

Fonte: Instagram (2018. Disponível em: https://instagram.com/minasfazciencia/. Acesso em: 3 dez. 2019.

A identidade visual do conteúdo é única e planejada para "amarrar" as diferentes narrativas, que respeitaram as características e linguagens de cada meio. A designer da equipe foi responsável pela criação de um elemento visual condutor da história. Ela projetou, desenhou e deu vida ao personagem João, que passeia pela área devastada guiado por um "pássaro da esperança". A navegação do João foi planejada para simular um processo intuitivo dos leitores que interagem com o Dossiê - em qualquer das mídias - numa viagem pelos cenários de reconstrução e recuperação do Rio Doce. Na revista, João "caminha", página a página, dentro do contexto da reportagem. No site, os desenhos são inseridos junto ao texto com uma ideia de complementaridade e, nas redes sociais, o personagem aparece como protagonista ao lado da informação científica.

\section{Nosso olhar sobre o Dossiê Rio Doce: pontos de partida para as análises}

Quando observamos a profundidade, continuidade, serialidade e o potencial de circulação dos produtos do Dossiê Rio Doce, percebemos que não se trata de uma narrativa midiática convencional. Considerando a presença de plataformas diversas, com características bastante distintas, a narrativa analisada começa com os textos e as ilustrações da revista impressa e se espalha em reescritas multissemióticas capazes de hierarquizar informações, com soluções bem compatíveis a cada suporte. É por isso que consideramos a produção como multimodal, pois foge de uma visão verbocêntrica, seguindo para uma construção verbo-visual com "manejo das linguagens à disposição, pela escolha de modos 
de expressão, assim como pela articulação entre o como e o que dizer" (RIBEIRO, 2016, p. 105).

Ademais, é uma narrativa multimídia porque há fluxos de informações entre distintas plataformas e suportes, com integração de processos e produtos que formam um continuum. "Nessa lógica de atuação conjunta, integrada, tem-se a horizontalidade perpassando os fluxos de produção, edição, distribuição, circulação, e recirculação dos conteúdos. O que se traduz, então, na noção de um continuum multimídia de cariz dinâmico” (BARBOSA, 2013, p. 36).

Ao escolher e delimitar o corpus em análise neste trabalho, reafirmamos o nosso reconhecimento da importância que as ilustrações desempenham na compreensão das informações contidas nas matérias jornalísticas. Por se tratar de um programa institucional de divulgação científica, o MFC tem, entre outros, o objetivo de aproximar a ciência e as pesquisas científicas dos públicos em geral. Além de utilizar diversas plataformas tecnológicas, o que lhe confere o caráter multimodal e multimidiático, são usados, também, no Dossiê, recursos gráficos e visuais que fazem com que o conjunto possa ser classificado como reportagens visuais, como pontuam Embury e Minichiello:

Uma reportagem baseia-se em eventos, ou seja, ela é uma arte aplicada a questões significativas que estejam acontecendo no mundo. O ilustrador age com um característico jornalista visual que registra, por meio da arte, a dinâmica dos eventos que transcorrem. $\mathrm{O}$ desenho de reportagem combina esboçar a aparência de uma cena com o esforço de entender e comunicar uma história por meio da linguagem visual (EMBURY; MINICHIELLO, 2018, p. 1).

Os autores defendem que os recursos visuais são adequados para representar salas de audiência, eventos públicos, documentários e reportagens e investigações jornalísticas. Sendo assim e considerando o forte teor jornalístico do corpus e seus recortes, entendemos que esses conceitos podem, sem nenhum deslocamento, ser utilizados na análise que pretendemos fazer. Ressaltamos aqui que compreendemos a importância das imagens na construção de narrativas jornalísticas, tanto no ambiente digital quanto em suporte impresso, e também os benefícios que o uso dos recursos visuais podem proporcionar aos leitores ao possibilitar uma leitura complementar e simultânea em outra linguagem, além dos textos verbais, uma vez que o desenho de reportagem pode ser utilizado para criar essa conexão e esclarecer questões difíceis e complexas (EMBURY; MINICHIELLO, 2018).

No caso do objeto em destaque, é importante ressaltar que o rompimento da Barragem do Fundão, no distrito de Bento Rodrigues, em Mariana/MG, além dos danos ambientais, das perdas humanas e da destruição das memórias afetivas, entre outras, fez com que se gerasse uma grande comoção social em torno do assunto, que foi pauta diária na cobertura dos veículos de comunicação de Minas Gerais e de todo o Brasil. Como a cobertura do que chamamos de factual (acontecimentos diários e suas reverberações) foi exaustiva, especialmente no que diz respeito aos danos e às perdas, a escolha do tema para a construção de um dossiê no âmbito do programa MFC abordou pesquisas selecionadas para que se pudesse pensar, em alguma medida, na recuperação da extensa área atingida pela lama e pelos rejeitos da mineração. Uma das autoras do artigo é membro da equipe Minas Faz Ciência, o que imprime ao estudo uma perspectiva interna do campo editorial da divulgação científica, mais especificamente do jornalismo sobre ciência. Este olhar é, por vezes, necessário e exige coragem para ver com ares mais objetivos uma prática que é tão próxima. 
O recorte é dado pela própria institucionalidade do objeto, inserido no contexto da divulgação científica sob a tutela da agência de fomento (FAPEMIG). O Minas Faz Ciência é um projeto nascido em 1998 por meio de uma série de vídeos produzidos em parceria com a Rede Minas. Surgem, em seguida, a revista impressa, um ciclo mensal de palestras e uma página na internet. Tal proposta se amplia em 2011, com o surgimento dos podcasts Ondas da Ciência, dos programas audiovisuais Ciência no Ar, do blog Minas Faz Ciência e da inserção do programa no Twitter e no Facebook. Em 2016, além do investimento no Instagram, o blog foi transformado em site e, atualmente, conta com publicações diárias na versão regular e infantil - dedicada ao público de 7 a 11 anos.

Muitas iniciativas ligadas à divulgação da ciência despontaram nas últimas duas décadas, mas ainda estamos longe de um trabalho que chegue a amplos setores da população brasileira. Segundo Massarani e Moreira (2002, p. 9), esse modelo de comunicação é frequentemente visto como uma atividade voltada sobretudo para o marketing científico de instituições, grupos e indivíduos ou como uma "empreitada missionária de alfabetização de um público encarado como um receptáculo desprovido de conteúdo".

Não se considera neste estudo a visão de divulgação científica como um processo tradutório. Ao contrário, corrobora-se com a necessidade de o jornalista científico não ser apenas um "hábil cativador de audiências, um esperto simplificador de conceitos, um tradutor de termos e dados para linguagem comum" (CASTELFRANCHI, 2008, p. 11). O jornalista científico não pode apenas informar. Precisa indagar a ciência e seus procedimentos, contextualizar e contar as histórias de maneira interessante, além de, no contexto digital, oferecer multimodalizações do texto que justifiquem a produção naquele ambiente.

Sobre o Dossiê Rio Doce, é mais pertinente lidar com o conceito de transcriação, termo cunhado e teorizado por Haroldo de Campos para o campo literário, mas transportado às práticas do jornalismo científico por Silva e Antunes (2016). Para os autores, o "território" da divulgação da ciência se alimenta de recriação de discursos, com o intuito de ampliar a capacidade de compreensão, pelos públicos, de certas nuances da produção do conhecimento. Nesse sentido, o uso de ilustrações faz parte das escolhas jornalísticas para a determinação de "lugares" próprios a cada assunto da ciência.

Parte-se, por fim, do entendimento de edição jornalística não apenas como prática responsável por definir espaços e dimensões das narrativas em diversos formatos [...], mas, também, como forma de mediação apta a explorar possibilidades de estímulo ao diálogo entre a ciência ("universo" composto por especialistas, instituições, etc.) e a sociedade (SILVA JR.; ANTUNES, 2016, p. 4).

A revista impressa é o objeto que conduzirá prioritariamente a análise proposta, por ser o produto carro-chefe do Dossiê, que aliás aqui se compreende como uma forma de sequenciação textual ou reportagem especial dentro da narrativa jornalística. $\mathrm{O}$ trabalho sobre o Rio Doce tem características de serialidade (MACHADO, 1999) - um conceito adaptado dos gêneros televisivos - que diz respeito à apresentação fragmentada do texto jornalístico e cria um contrato especial entre jornalista e leitor. Machado definiu serialidade como:

No caso específico das formas narrativas, o enredo é geralmente estruturado sob a forma de capítulos ou episódios, cada um deles apresentado em dia ou horário diferente e subdividido, por sua vez, em 
blocos menores, separados dos outros por breaks para a entrada de comerciais ou de chamadas para outros programas (MACHADO, 1999, p. 15).

Toma-se aqui emprestado o conceito para discutir o uso dessa estratégia na produção do Dossiê Rio Doce, pensado e produzido como blocos que fazem parte de um enredo estruturado. Para Machado (1999), as narrativas seriadas abrangem três grandes categorias: aquelas fundadas nas variações em torno de um eixo temático, aquelas baseadas na metamorfose dos elementos narrativos (personagens, espaço, tempo) e as estruturadas na forma de um entrelaçamento de situações. No Dossiê Rio Doce é possível identificar que a condução seriada se dá pela temática, além dos elementos narrativos visuais, como a figura do João.

Na narrativa seriada, a produção é singularizada, ela é definida como especial porque o produtor agrega valor ao material. A serialização, aliás, faz parte da estética audiovisual contemporânea, contendo elementos que possibilitam a continuidade de produtos e obras por meio de capítulos, episódios e temporadas. Atualmente, é reflexo também de mudança de comportamento do consumidor e do novo paradigma midiático ligado à cultura da convergência (JENKINS, 2008). Há uma demanda por histórias amarradas pela possibilidade de participação e cocriação, além da chance do registro de memória em produções multimídia e multimodais.

No caso do Dossiê Rio Doce, o site tem a função de apresentar os bastidores de construção da reportagem da revista, funcionando como paratexto no sentido de trazer informações contextuais que, em maior ou menor grau, alteram a significação. Genette (2009) considera como paratextos factuais aqueles que incrementam contexto implícito ao texto original e que não necessariamente precisam ser conhecidos, mas que mudam perspectivas de leitura.

Deve-se pelo menos ter em mente o valor paratextual que outros tipos de manifesto podem conter: icônicas (as ilustrações), materiais (tudo o que envolve, por exemplo escolhas tipográficas, por vezes muito significativas, na composição) ou apenas factuais. Chamo de factual o paratexto que consiste, não numa mensagem explícita (verbal ou não), mas num fato cuja própria existência, se é conhecida pelo público, acrescenta algum comentário ao texto e tem peso em sua recepção (GENETTE, 2009, p. 14).

Por fim, as publicações em redes sociais digitais do Dossiê Rio Doce são aqui vistas como elementos de ampliação da circulação e performance, ou seja, caminhos para levar o leitor à revista. A circulação do texto jornalístico se refere à capacidade de esse conteúdo se espalhar intermidiaticamente, adquirindo notoriedade à medida em que é compartilhado em rede. Para Alzamora (2012, p. 53), esse compartilhamento se refere "a uma forma ativa de audiência, que confere valor e adiciona conteúdo às informações que replica". A performance está relacionada ao alcance e à audiência desse texto, na medida em que ele é planejado para atrair leitores na rota do ambiente digital. Especialmente para o Dossiê Rio Doce, não há intenção de conversão de leitores, em sentido comercial, porque o Minas Faz Ciência não tem esse objetivo. Performance se refere muito mais a levar ciência ao maior número de leitores possíveis como efeito ideal para um projeto de divulgação científica. 


\section{Uma possibilidade de leitura visual para Dossiê Rio Doce}

Partindo do entendimento da "função" de cada produto no Dossiê - revista impressa como carro-chefe, site como paratexto e redes sociais como ferramentas de circulação, seguimos para as análises visuais sem perder de vista os conceitos base de reportagem visual, transcriação, serialidade, multimodalidade e multimidialidade.

O conceito de imagem de Joly (2012) é bem adequado para nossa análise, uma vez que um personagem João foi criado para conduzir o leitor durante o percurso da leitura das narrativas. Ainda que seja um desenho, representações de características humanas estão presentes na imagem. Além disso, o personagem que se aproxima de um desenho infantil pode, em alguma medida, trazer leveza e ludicidade a um assunto grave, que gerou intensa comoção social. No aspecto da recepção, muito embora não seja esse o foco principal deste trabalho, poderíamos pensar que a presença do personagem pode fazer com que a leitura seja mais agradável para os leitores.

Pensando o aspecto da reportagem ilustrada, conceito trazido por Embury e Minichiello (2018), e como jornalistas que somos, reconhecemos o valor e a importância das infografias na construção das narrativas jornalísticas, uma vez que essas são ferramentas e meios que auxiliam os leitores na compreensão dos assuntos abordados nas matérias. No caso da divulgação científica, as infografias cumprem a função, em muitos casos, de auxílio na decodificação das informações apresentadas e que, em diversas situações, estão relacionadas a assuntos que não fazem parte do cotidiano da maioria das pessoas.

Importante é não confundir nosso objeto de pesquisa com as revistas ilustradas que circularam no Brasil e no mundo que preconizam o uso da imagem fotográfica em suas páginas. Embora haja fotografias, elas apenas reforçam o caráter de multimodalidade do objeto, mas não predominam sobre a condução da leitura feita pelo personagem criado, João, especialmente e exclusivamente para o Dossiê.

Embora o assunto do rompimento da barragem do Fundão, bem como todas as reverberações registradas, não apenas factualmente, mas no período que se seguiu ao acontecimento, tenha provocado comoção social e atingido as pessoas, de uma forma geral, a cobertura se limitou ao fato e suas consequências, especialmente aos danos ambientais. Daí a decisão editorial da Minas Faz Ciência de abordar o assunto a partir da perspectiva da recuperação, da existência de esperança de "renascimento" a partir do trabalho de pesquisadores envolvidos com projetos capazes de minimizar as consequências dos danos ambientais.

\section{Revista}

Especialmente sobre a revista, vale a pena ser registrada a escolha das cores que norteou a execução do projeto editorial no que diz respeito ao aspecto visual: o marrom, associado à lama e aos rejeitos da mineração, apareceu apenas na capa da primeira edição do Dossiê Rio Doce, mas para dar espaço a uma pequena planta, verde, simbolizando a esperança. $\mathrm{O}$ marrom foi substituído pelo verde e pelo azul, cores relacionadas à vida e à esperança (figura 6 ). 
Figura 6 - Trecho do Dossiê, páginas 30 e 31 da edição 73.

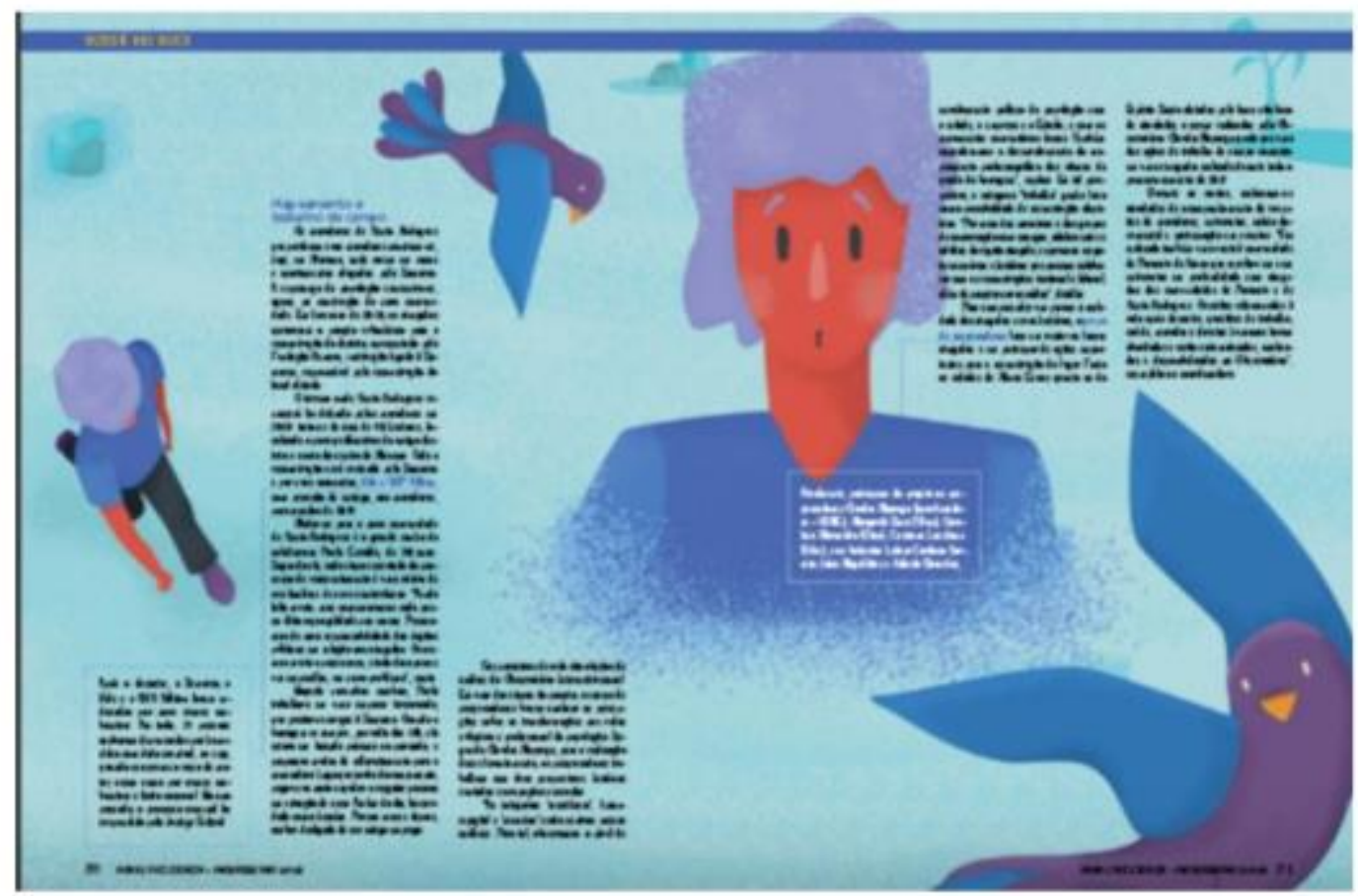

Fonte: FAPEMIG (2018). Disponível em: https://issuu.com/fapemig. Acesso em: 3 dez. 2019.

Para além das cores, observa-se que a linguagem usada na revista tenta contextualizar e contar as histórias de maneira interessante. É, também, uma produção preocupada com a articulação entre o como e o que dizer, aspecto primordial à divulgação científica. Na edição 73 , por exemplo, ao explicar uma metodologia científica, a autora do texto opta por falar dos métodos como perspectivas usadas pelos pesquisadores para entender a realidade dos atingidos pela lama. Com esse recurso, visa aproximar o leitor de uma realidade muito restrita ao meio acadêmico, os mecanismos metodológicos.

Segundo Claudia Mayorga, para a realização desse levantamento, os pesquisadores trabalham com duas perspectivas: histórias contadas e ocupações exercidas. As categorias "resistência", "emancipação" e "memória" serão centrais nessas análises. Para tal, observamos o nível de envolvimento político da população com a cidade, a empresa e o Estado, e com os movimentos comunitários locais. Também consideramos o desenvolvimento do mapeamento profissiográfico das vítimas da queda da barragem", explica. Em tal perspectiva, a categoria "trabalho" ganha foco como possibilidade de reconstrução identitária (Trecho da revista, reportagem "Em Águas Limpas", edição 73, p. 30).

$\mathrm{Na}$ edição 74, ao contextualizar a pesquisa sobre aquaponia, o texto faz referência ao nome dado pelos índios ao sistema de tanques que promove a criação de espécies aquáticas dizimadas pela lama da mineração: "Desde o início do ano, contudo, a realidade da aldeia Atorã - uma das sete que compõem a tribo - tem se modificado, por conta do sistema chamado pelos índios de "Bok'ererre", ou "peixe bom" (Trecho da revista, reportagem "Em águas limpas", edição 74, p. 37). O texto humaniza os impactos da ciência para a comunidade indígena e mostra ao leitor que, naquele caso, ocorreu uma interação entre ciência e sociedade. 
Percebe-se ainda que recursos gráficos e editoriais auxiliam a construção verbovisual, sendo alguns deles tradicionais para o gênero revista como versais, olhos, boxes e integração da ilustração com as palavras, mas outros nem tanto, como o caso do hipertexto. Um exemplo está na edição 75 , em que um quadro no meio do texto explica a expressão "estudo fitossociológico" (figura 7). O bloco aparece como uma expansão de significado do termo ou informação complementar. É dada ao leitor a opção de "navegar" por esta referência a qualquer momento da experiência de leitura, algo muito análogo à função dos biperlinks em textos no ambiente digital. Aliás, ressalta-se que este recurso aparece em outros três momentos do Dossiê.

Figura 7 - Recurso hipertexto, edição 75.

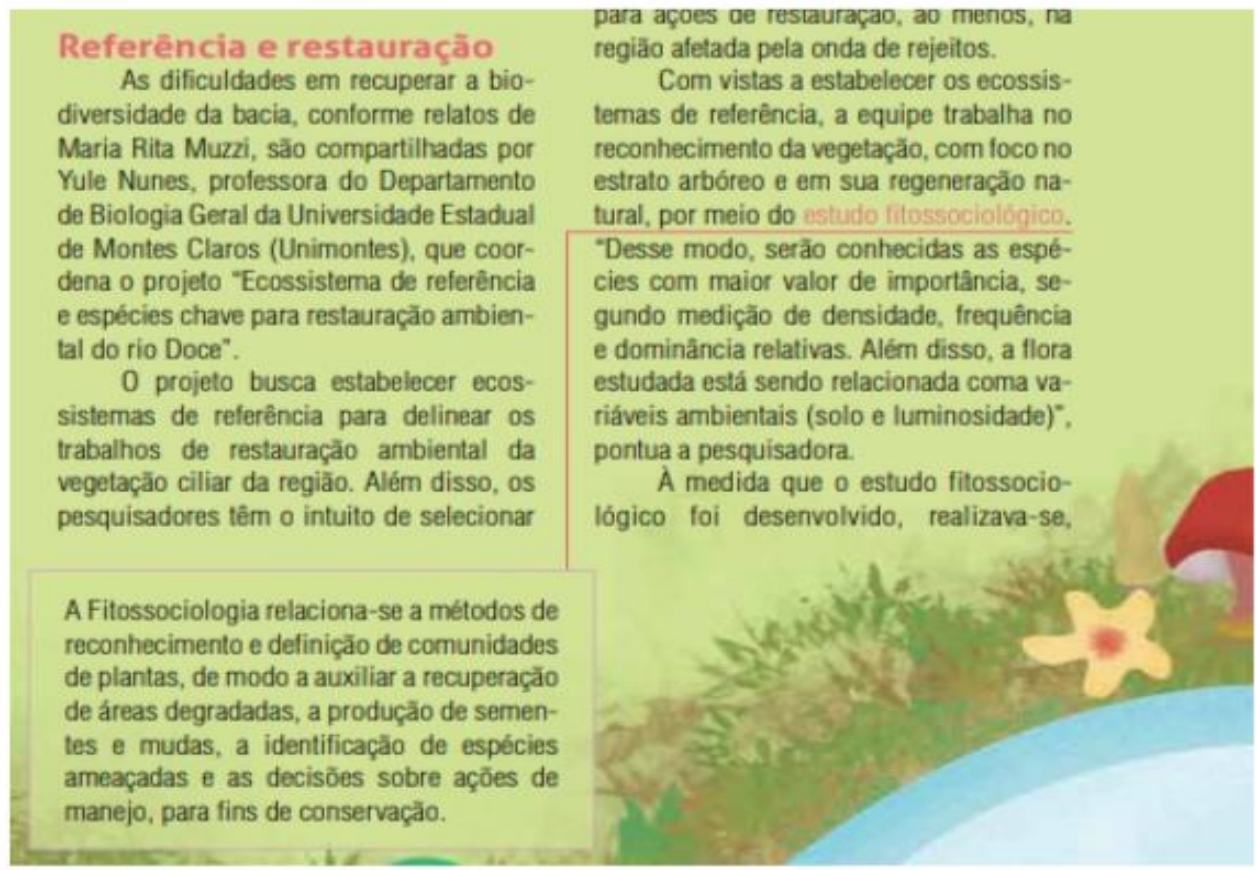

Fonte: FAPEMIG (2018). Disponível em: https://issuu.com/fapemig. Acesso em: 3 dez. 2019.

Enfim, as multimodalizações do texto na revista justificam o modo de produção daquela mídia e contribuem para a afirmação do Dossiê como reportagem visual. Os processos de escrita e edição, em que forma e conteúdo são pensados de maneira integrada, valorizam os jogos de linguagem para promover comunicação e produção de sentido.

\section{Site}

O especial "Expedição Rio Doce" está publicado em local de destaque no site do projeto MFC e conta com material em textos, vídeos e fotos, em uma narrativa multimodal. A equipe de jornalistas - uma repórter e um cinegrafista - viajou com pesquisadores e passou três dias no Parque Estadual do Rio Doce, registrando o trabalho de campo que tinha como objetivo coletar folhas e sementes de espécies vegetais típicas da Mata Atlântica para realizar estudo sobre a importância dos fungos na preservação ambiental. 
Como já dito anteriormente, o nosso entendimento é que esse material verbo-visual atua como um paratexto da narrativa multimídia, uma vez que o relato é feito em primeira pessoa pela repórter, como se o texto fosse, na verdade, um diário de bordo (figura 8) em que ela relata as experiências vivenciadas por ela e também detalhes da expedição, como dificuldades e os preparativos para os trabalhos, ou seja, os bastidores da expedição. Além do caráter testemunhal, é importante ressaltar, no texto, a presença de informações e dados científicos, mas em linguagem clara e acessível aos leitores do site e do Dossiê Rio Doce.

Figura 8 - Trecho do relato publicado no site do MFC.

\begin{abstract}
Mal apontavam os primeiros raios de sol no horizonte, e eu já acordava, naquela terçafeira. 8 de maio de 2018. Etapa do projeto "Mycoendosimbiosis preservação da biodiversidade de fungos endofiticos e suas plantas hospedeiras presentes em fragmento nativo da Mata Atlântica do estado de Minas Gerais". a expedição ao Parque Estadual do Rio Doce (Perd) começaria cedo: 7 h30.
\end{abstract}

Antes de partir, porém. muito trabalho aguardava a equipe. composta por seis pesquisadores do Instituto de Ciências Biológicas (ICB) da Universidade Federal de Minas Gerais (UFMG). Afinal, é preciso organizar os materiais necessários às coletas, a serem realizadas durante os três dias de expediçăo: sacos plásticos, lamparina, podão, fita crepe, tesouras, perneiras e muito, muito repelente!

O Parque fica na regiăo mineira conhecida por Vale do Aço, a 248 km de Belo Horizonte. Trata-se de uma das maiores áreas continuas de Mata Atlântica do Brasii, com cerca de 36 mil hectares.

Atualmente, encaixa-se na categoria de Unidade de Conservação Ambiental, devido a sua imensa biodiversidade e a seu sistema lacustre. composto por 42 lagoas, em especial a Dom Helvécio. Com o rompimento da barragem de minérios da Samarco, em novembro de 2015, 40 milhōes de metros cúbicos de lama invadiram e contaminaram o rio que corta e dá nome ao Perd.

Fonte: FAPEMIG (2018). Disponível em: http://minasfazciencia.com.br/expedicao-rio-doce/. Acesso em: 3 dez. 2019.

O conteúdo e a narrativa textuais são acompanhados por elementos imagéticos, objetos principais desta análise, que trazem uma complementaridade das informações, a saber: a presença do personagem João, o que confere identidade visual ao material publicado no site; o uso de imagens fotográficas e de vídeos curtos.

No caso das fotografias, o destaque é para imagens aéreas que mostram a exuberância das florestas e das águas do Parque Estadual do Rio Doce (figura 9). Há também imagens que mostram a equipe de pesquisadores e uma que mostra um bicho-preguiça, apresentando a riqueza da fauna local. Já o material audiovisual é composto por cinco vídeos curtos que trazem apresentações, simples e objetivas, dos projetos desenvolvidos no parque pelas equipes de pesquisadores.

A presença dessas imagens, bem como o significado que representam, corroboram a proposta inicial do Dossiê Rio Doce: mostrar as possibilidades, especialmente, de recuperação ambiental da bacia, bem como lembrar ao leitor da beleza das riquezas naturais e da importância socioeconômica que a bacia hidrográfica tem para a população. 
Figura 9 - Fotografia publicada no site Expedição Rio Doce.

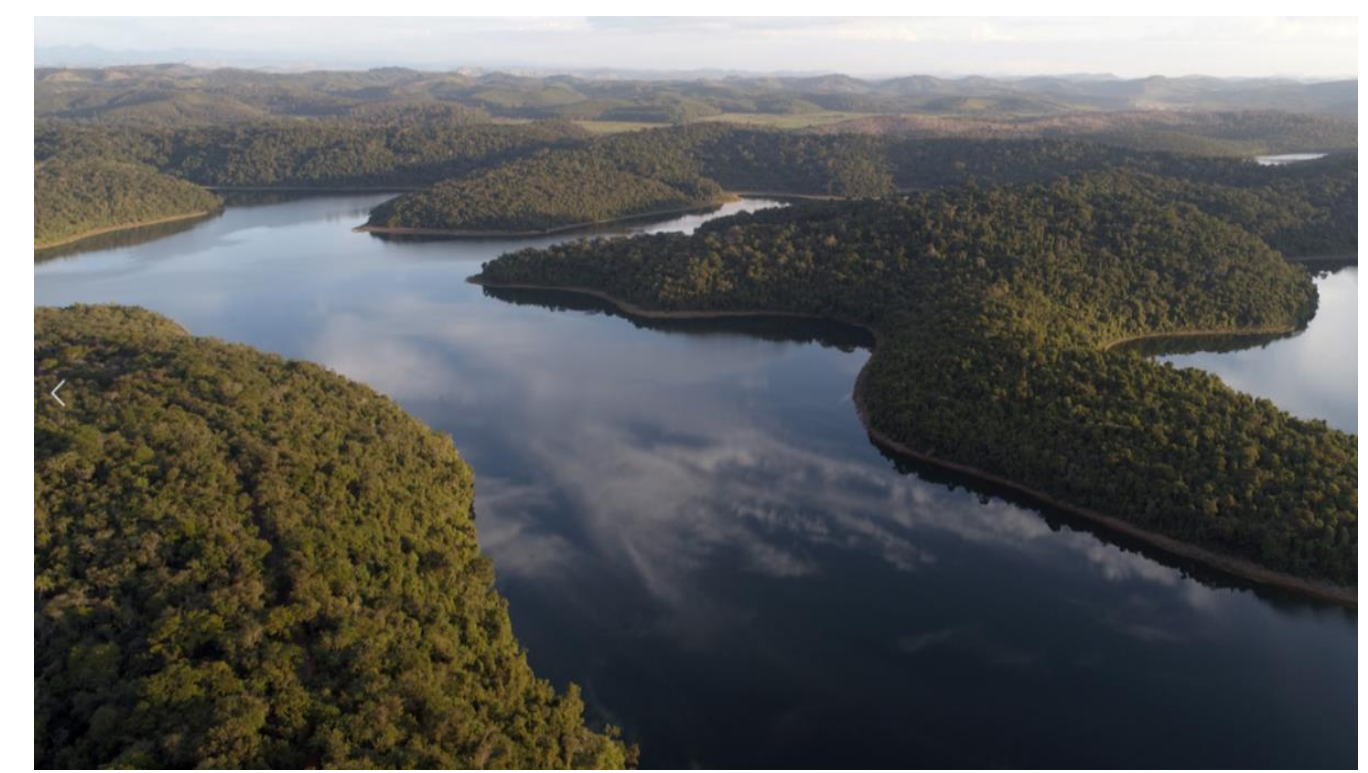

Fonte: FAPEMIG (2018). Disponível em: http://minasfazciencia.com.br/expedicao-rio-doce/. Acesso em: 3 dez. 2019.

As narrativas visuais são utilizadas para fazer com que a narrativa completa seja mais atraente e, em certa medida, tenha mais possibilidades de ser melhor compreendida pelos leitores. Considerando que o consumo de material imagético tem aumentado significativamente, o uso desses recursos no Dossiê Rio Doce tem papel fundamental para aumentar o alcance da publicação. Somente no Brasil, de acordo com dados do Instituto Brasileiro de Geografia e Estatística (IBGE), divulgados em dezembro de 2018, o país tinha 126,4 milhões de usuários de internet (69,8\% da população com 10 anos ou mais) e os smartphones são os dispositivos mais utilizados para acesso à internet (98\%). Do total de acessos, o maior número se refere ao envio de mensagens por diferentes aplicativos, ou seja, redes sociais, onde circulam o maior número de imagens - fotografias e vídeos.

\section{Redes sociais}

No caso do Facebook, a escolha pelo vídeo animado pode ser uma opção alinhada às demandas da mídia social e ao consumo em ambiente digital. A visualização de vídeos cresceu mais de 90\% nos últimos anos e, temporariamente, o próprio algoritmo da plataforma privilegiou o formato por entender que as pessoas queriam mesmo assistir a conteúdos. Além disso, o uso do personagem João em movimento propicia uma experiência verbo-visual não experimentada pelo Minas Faz Ciência anteriormente. Não é exatamente um vídeo que ajudará a comunicar a história presente no Dossiê Rio Doce, mas servirá como chamada ao leitor interessado em mergulhar na narrativa jornalística. Sendo assim, reforçase o caráter atrator das redes sociais para o conteúdo da revista impressa.

O vídeo reproduz a ideia intrínseca ao Dossiê de percorrer os ambientes devastados pela lama em Mariana (figura 10). O personagem animado corre pelos cenários que são, na verdade, as páginas da revista Minas Faz Ciência. Outras modalidades de linguagem contidas nos produtos do Dossiê não conseguem expandir movimento, caráter modal explorado apenas no post do Facebook. É uma espécie de "mostração" da edição 73 cumprindo a integração de processos e produtos que formam um continuum multimídia do Dossiê. A 
produção faz também uma remissão dialógica entre mídias, resgatando o passar de folhas da revista impressa.

Figura 10 - Reprodução de vídeo.

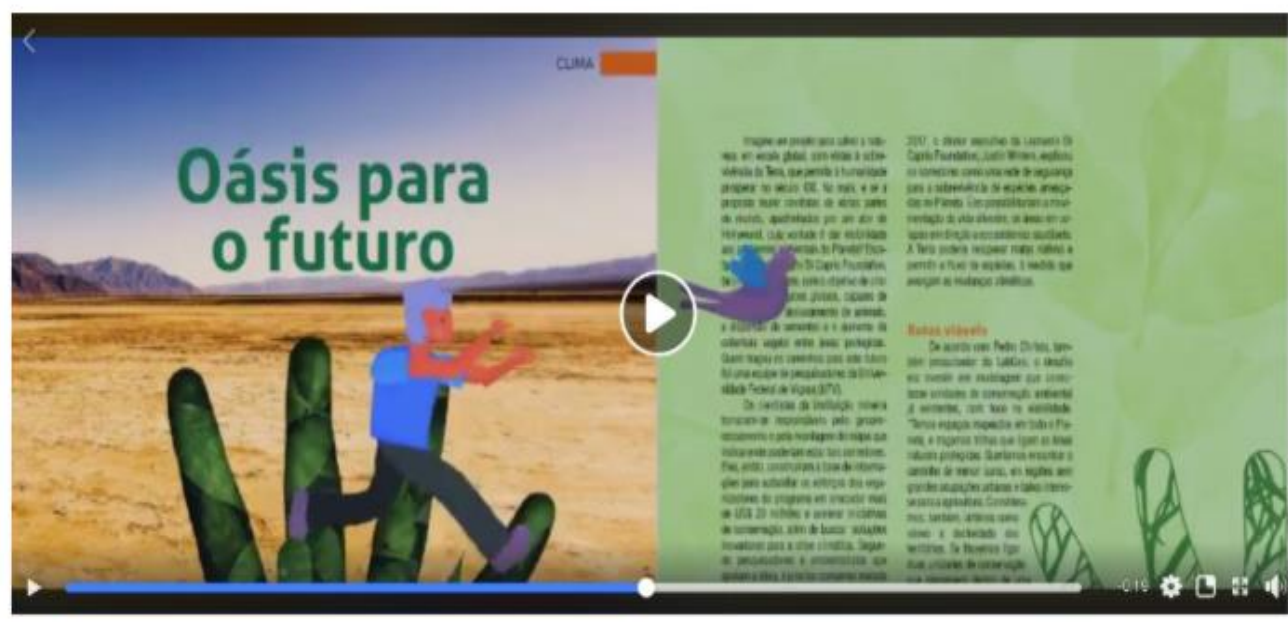

Fonte: FAPEMIG (2018). Disponível em: https://www.facebook.com/minasfazciencia. Acesso em: 3 dez. 2019.

O despertar de João no início do vídeo é uma referência intertextual à história da Teoria da Gravidade. É muito famosa a versão de que Isaac Newton teve um insight sobre as forças gravitacionais após ser atingido por uma maçã debaixo de uma árvore. Esta é uma marca dos processos de transcriação, recriar de discursos, neste caso, auxiliado pela ilustração e animação. Para este vídeo, recria-se o ambiente visual da revista impressa e, ainda, uma história presente no imaginário social coletivo.

No caso do Instagram, o uso da ferramenta mosaico singulariza a postagem, diferenciando de outros formatos presentes no feed Minas Faz Ciência. Este é o único mosaico existente no perfil, o que caracteriza o Dossiê como uma narrativa especial. Além disso, a ideia de serialidade é reproduzida por causa dos blocos de imagens recortadas que fazem parte de um enredo estruturado. É possível considerar a estratégia até como metalinguagem ao conceito de Dossiê.

A imagem postada no Instagram é a mesma contida nas páginas 32 e 33 da edição 73 da revista. Na versão impressa, são listados projetos científicos de recuperação da bacia do Rio Doce, muitos deles são abordados nas reportagens seguintes do Dossiê. No feed da rede social, a listagem é remodalizada em imagens individuais que podem ser deslizadas pelo leitor, uma possibilidade de experiência própria do Instagram.

Observa-se, por fim, que a peculiaridade dos produtos apresentados nas duas plataformas de redes sociais responde ao manejo das linguagens à disposição em cada uma delas. Em ambos casos, sem perder o foco na integração com o material apresentado na revista e no site. 


\section{Considerações finais}

Iniciamos este breve estudo com a ideia de que a presença de elementos visuais é fundamental à compreensão e ao consumo das narrativas jornalísticas. O percurso de análise do Dossiê Rio Doce ajudou a reforçar essa noção, considerando todos os elementos encontrados na revista, site e plataformas de rede sociais. As cores, os usos do personagem criado exclusivamente para a narrativa e o aproveitamento de linguagens à disposição no ambiente digital comprovaram a construção de uma reportagem visual de caráter multimídia e multimodal. Cada parte dessa reportagem visual - revista como carro-chefe, site como paratexto e redes sociais como elemento de ampliação e circulação - compôs um processo transcriativo muito pertinente à divulgação científica.

Considerando ainda que o consumo de material imagético é cada vez maior e mais frequente nas sociedades contemporâneas, acreditamos que o uso desses recursos fotografia, desenhos ou ilustrações, material audiovisual, entre outros - será cada vez mais frequente nas narrativas jornalísticas, inclusive naquelas de divulgação científica, como possibilidade de aproximar os leitores do conteúdo publicado em diversas plataformas.

No caso do objeto em estudo, acreditamos que a presença de narrativas visuais e de imagens ilustrativas em todas as plataformas utilizadas para a publicação do Dossiê Rio Doce nos apontam, embora não tenhamos feito estudo de recepção, que são ferramentas que possibilitam melhor compreensão dos projetos realizados ao longo da Bacia do Rio Doce para sua recuperação ambiental e social.

\section{Referências}

ALZAMORA, G. C. Especificidades da rede intermídia contemporânea: Considerações sobre a audiência em contextos reticulares. Revista Latinoamericana de Ciencias de la Comunicación, v. 9, n. 2, p. 50-61, jul./dez. 2012.

BARBOSA, S. Jornalismo convergente e continuum multimídia na quinta geração do jornalismo nas redes digitais. In: CANAVILHAS, João (Org.). Notícias e mobilidade: o jornalismo na era dos dispositivos móveis. Covilhã: Livros LabCom, 2013.

CAMARGO, I. A. A definição do conceito de objeto noticioso na mídia impressa. 2001. Disponível em: http://www.compos.org.br/data/biblioteca_1339.pdf. Acesso em: 3 dez. 2019.

CASTELFRANCHI, Y. Para além da tradução: o jornalismo científico crítico na teoria e na prática. In: MASSARANI, L.; POLINO, C. (Org.). Los desafíos y la evaluación del periodismo científico en Iberoamérica. Jornadas Iberoamericanas sobre la ciencia en los medios masivos. Santa Cruz de la Sierra: AECI, RICYT, CYTED, SciDevNet, OEA, 2008.

EMBURY, G.; MINICHIELLO, M. Reportagem Ilustrada - Do desenho ao jornalismo: princípios básicos, técnicas e recursos. São Paulo: Gustavo Gili, 2018.

GENETTE, G. Paratextos Editoriais. Cotia: Ateliê Editorial, 2009.

JENKINS, H. Cultura da convergência. São Paulo: Editora Aleph, 2008. 
JOLY, M. Introdução à análise da imagem. Tradução: Marina Appenzeller. Campinas: Papirus, 2012.

MACHADO, A. Pode-se falar em gêneros na televisão? Revista Famecos, v. 6, n. 10, p. 142-158, 1999.

MASSARANI, L.; MOREIRA, I. C. Apresentação. In: MASSARANI, Luisa et al. Ciência e público: caminhos da divulgação científica no Brasil. Rio de Janeiro: Casa da Ciência Centro Cultural de Ciência e Tecnologia da Universidade Federal do Rio de Janeiro (UFRJ), 2002. p. 43-64.

RIBEIRO, A. E. Textos multimodais: leitura e produção. São Paulo: Parábola Editorial, 2016.

SILVA Jr., M. G.; ANTUNES, E. Do desejo de traduzir à transcriação: apontamentos sobre a decodificação jornalística do discurso científico, com base em conceitos de Haroldo de Campos, José Paulo Paes e Paul Ricoeur. E-Compós, Brasília, v. 19, n. 2, maio/ago. 2016. 